\title{
AN ALTERNATIVE APPROACH TO CALCULATING PEAK BONE MINERAL DENSITIES AND PEAK BONE MASSES
}

\author{
Dilruba Akhter Banu \\ Department of Physics \\ University of Rajshahi, Rajshahi-6205, Bangladesh
}

\begin{abstract}
Polynomial regression analyses, commonly used for curve fitting in Bone Mineral Density (BMD) versus Age or Bone Mineral Content (BMC) versus Age graphs, do not seem to be entirely satisfactory. Instead, LOESS (Locally Weighted Smoothing) regression works better in depicting the trend in experimental results. Bootstrapping method has been employed to generate 100 samples from each set of data obtained from DEXA machines located in different parts of Bangladesh and these have been analyzed using Loess regression to calculate the peak bone mineral density and peak bone mass along with the ages at which they appear at $\mathbf{9 5 \%}$ confidence intervals. Results have been discussed in the light of previous ones.
\end{abstract}

Keywords-BMD, BMC, Osteoporosis, Loess, Bootstrapping, T-score

\section{INTRODUCTION}

Peak Bone Mineral Density (pBMD) and Peak Bone Mineral Content/Mass (PBM) are important parameters, indicative of the bone health of a population. The greater are the values of these parameters; the better is the bone health of that population. pBMD is important from another point of view. It is used to calculate the T-score defined by the relation,

T-score $=$ (measured BMD - mean BMD of young healthy reference group) / standard deviation [1].

According to $\mathrm{WHO}$, a person with a T-score of -1.0 and above is normal, with a T-score within the range, -1.0 and -2.5 , has low bone density or osteopenia and with a T-score of -2.5 and below is suffering from osteoporosis, a bone disease that makes the bone brittle [2]. The problem arises as to how to choose this "mean BMD of young healthy reference group", because there is no universal value. This 'mean BMD' which is nothing but pBMD has been found to depend on sex and ethnicities [3, 4]. Thus to calculate a person's T-score, his ethnicity and sex has to be kept under consideration $[5,6]$. HoPham et al [7] have shown for Vietnamese men and women that improper reference values can yield results that can lead to wrong diagnosis of osteoporosis. As far as we know, no such reference value exists in Bangladesh. In our previous paper [8], we calculated pBMD using the traditional method of polynomial regression. In the present paper we have used the LOESS (Locally Weighted Smoothing) curve fitting method.

Although pBMD $\left(\mathrm{g} / \mathrm{cm}^{2}\right)$ and PBM $(\mathrm{g})$ are closely related, their relationship may not be exactly linear. BMC depends on both the size and density of the skeletal bone and differs because of either bone size or bone density. Thus it has been found that at the spine $86.2 \%$ of BMD variation is due to BMC and $12.6 \%$ to bone areal size, whereas at the hip it is 98 $\%$ and $1.1 \%$ [9]. An increase of PBM by one standard deviation is supposed to reduce the fracture risk by $50 \%$. We have therefore decided to estimate PBM as well by the new method.

\section{METHODS}

Details of the experimental procedure for measuring BMD and $\mathrm{BMC}$ have been discussed elsewhere [8]. R software was used for statistical analysis.

\section{RESULTS AND DISCUSSION}

A graph of BMD versus age for females has been shown in Fig. 1 where polynomials of degrees, 1-4 have been tried. None of the polynomials seems able to satisfactorily explain the pattern of variation, although most authors have used polynomial of degree 3 and a few have used degree 4 for curve fitting. It is common knowledge to anyone familiar with bone health that bone density increases from childhood to youth, remains steady for sometime and then gradually decreases in old age. The rate of increase in initial years is much higher than the rate of decrease in later years. Linear equation gives no maximum whereas the quadratic one gives a maximum followed by a much sharper fall than in real life. Both third and fourth degree polynomials predict an additional rise in BMD in contrast to reality. Loess curve which is given in Fig. 2 depicts the expected behavior. 


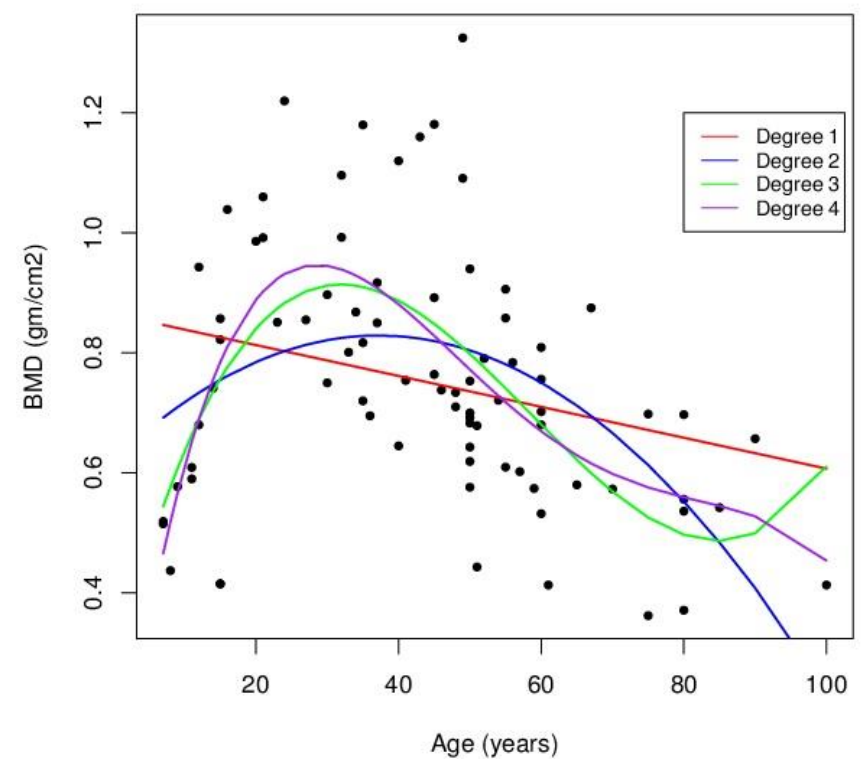

Fig. 1. BMD versus Age graph for female lumbar spine showing curve fitting by polynomials

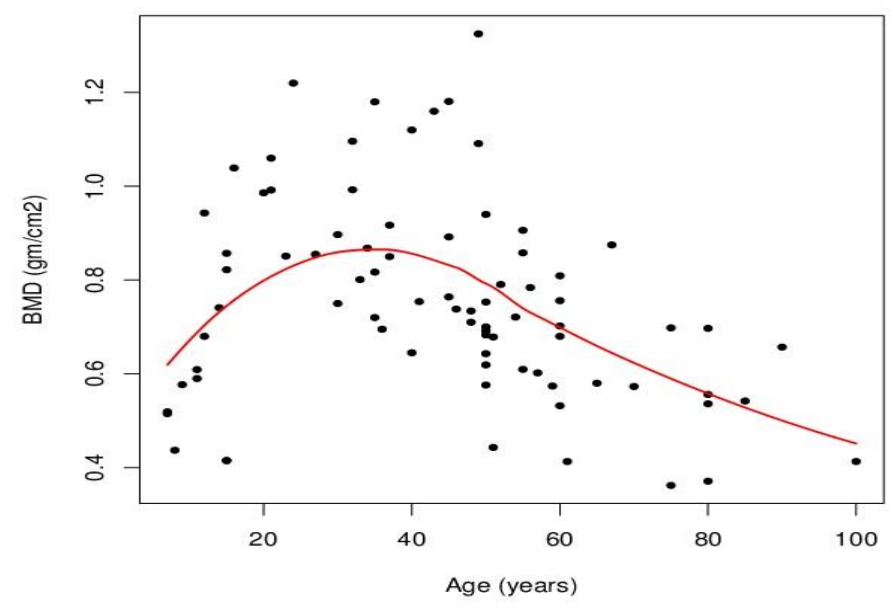

Fig. 2. Loess graph for BMD female

It is found on statistical analysis that although correlation gets better on going from first to fourth degree polynomial, $p$ values suggest no significant improvement. All these considerations lead us to conclude that Loess is the best alternative.

Fig. 3 shows the polynomial fitting of male lumbar spine results.

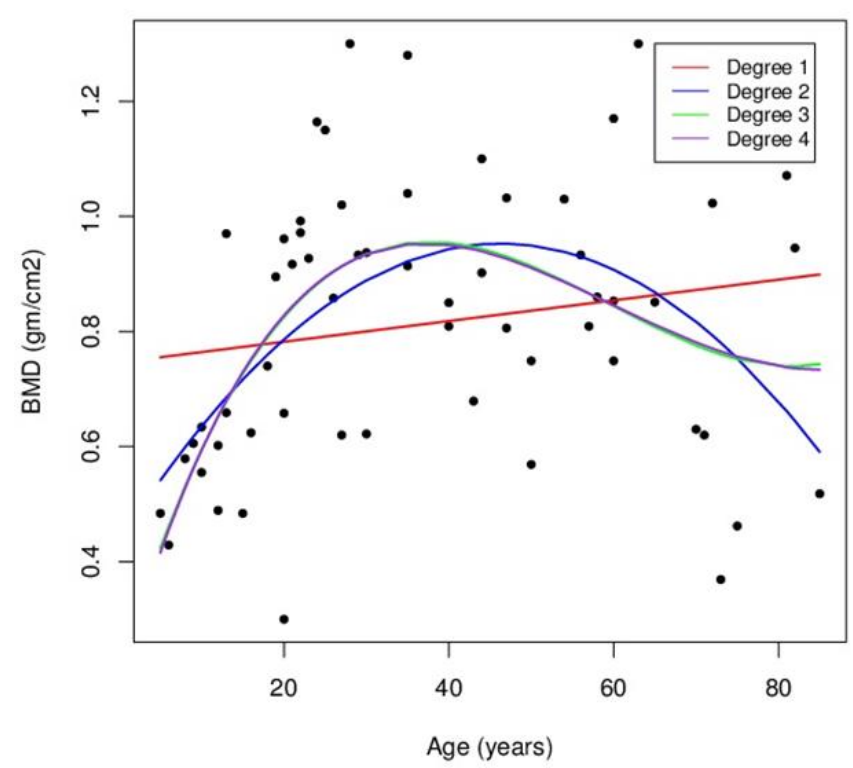

Fig. 3. BMD versus Age graph for male lumbar spine showing polynomial fitting

This figure is almost similar to Fig. 1 except that polynomials of degree 3 and 4 completely overlap each other.

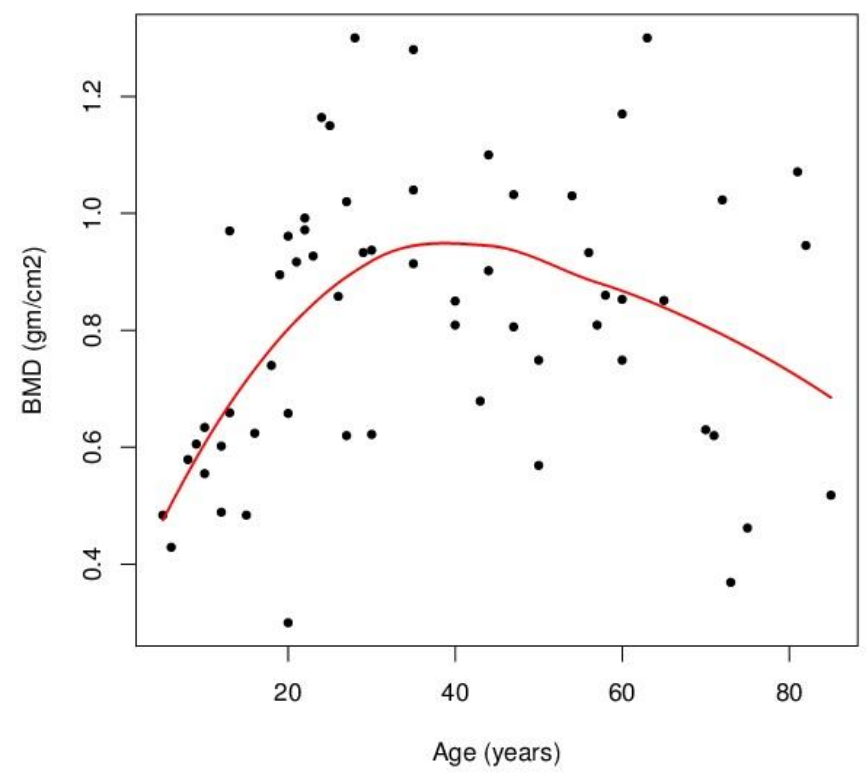

Fig. 4. Loess graph for BMD male

This graph is very similar to that in Fig. 2.

Graphs on Bone Mineral Content (BMC) have been shown in Figs. 5-8. 


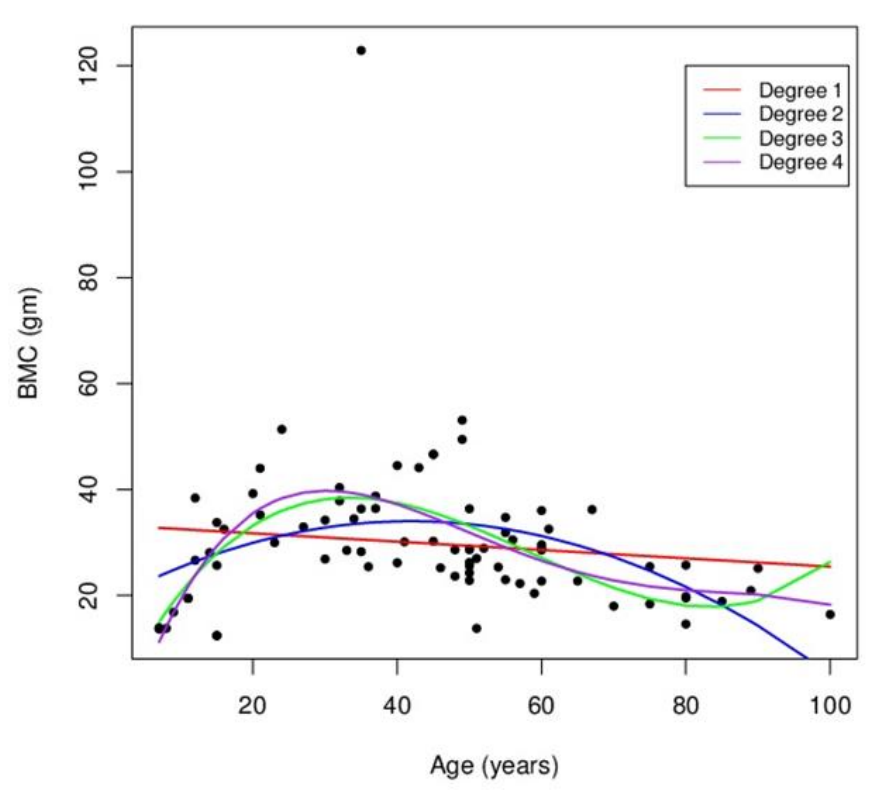

Fig. 5. BMC versus Age graph with polynomial fittings for female lumbar spine

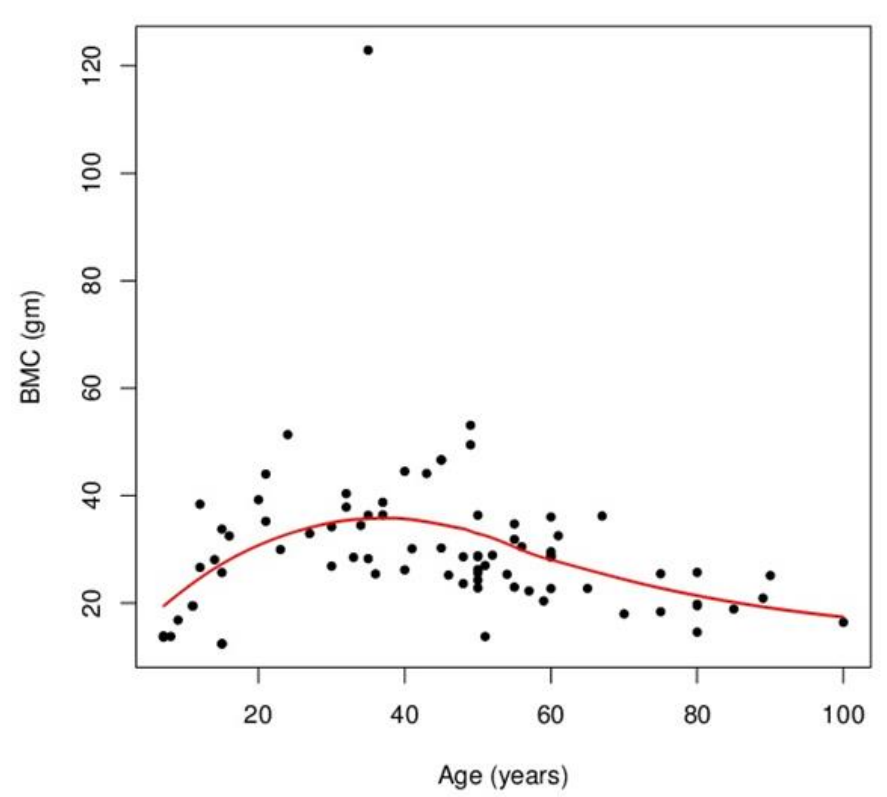

Fig. 6. Loess graph for BMC female

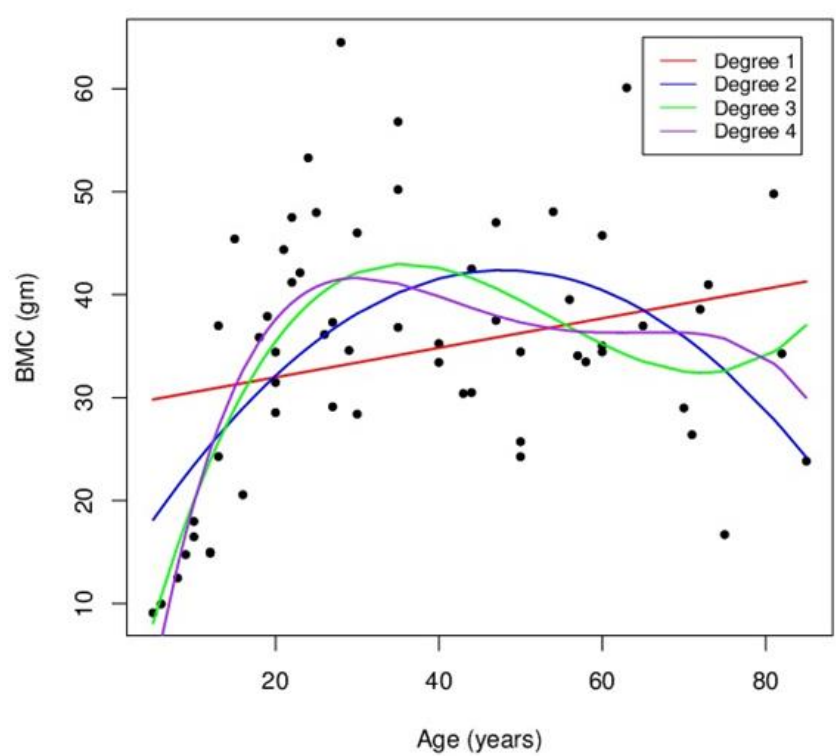

Fig. 7. BMC versus Age graph with polynomial fittings for male lumbar spine

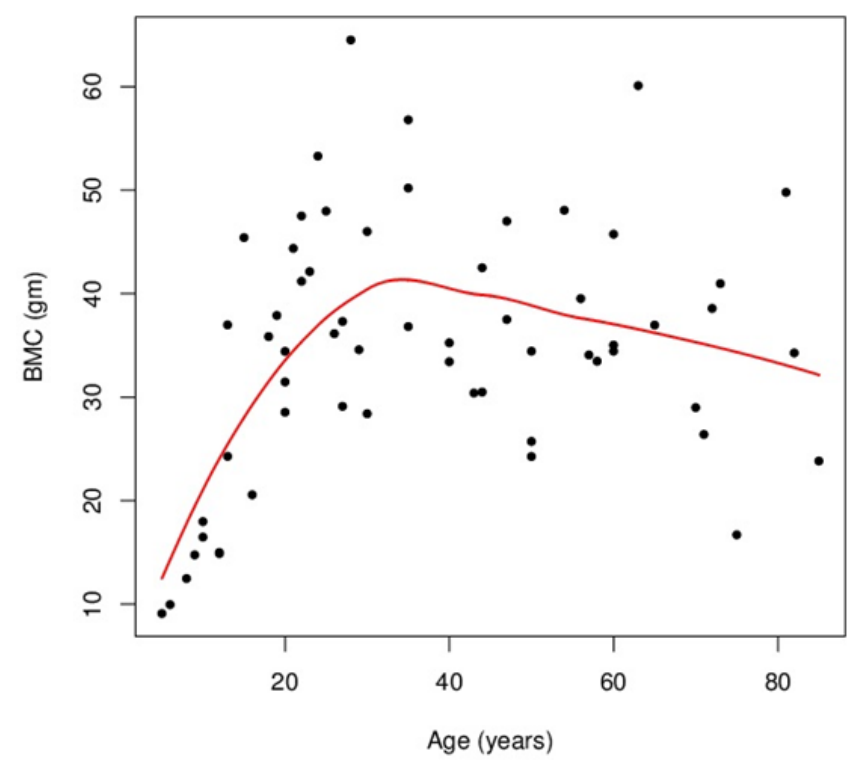

Fig. 8. Loess graph for BMC male

It would be seen that BMC graphs are similar to the corresponding female and male BMD graphs. Calculated values of pBMD and PBM along with their standard deviations and $95 \%$ confidence intervals are shown in Tables 1 and 2 . 


\section{International Journal of Engineering Applied Sciences and Technology, 2019 \\ Vol. 4, Issue 7, ISSN No. 2455-2143, Pages 316-320 \\ Published Online November 2019 in IJEAST (http://www.ijeast.com)}

Table 1. pBMD and Age of occurrence for female and male lumbar spine

\begin{tabular}{|c|c|c|c|c|c|c|c|c|}
\hline \multirow{2}{*}{ Sex } & \multicolumn{2}{|c|}{ Original sample } & \multicolumn{6}{c|}{ After bootstrapping } \\
\cline { 2 - 9 } & $\begin{array}{c}\mathrm{pBMD} \\
\left(\mathrm{g} / \mathrm{cm}^{2}\right)\end{array}$ & $\begin{array}{c}\text { Age } \\
\text { (years) }\end{array}$ & $\begin{array}{c}\mathrm{pBMD} \\
\left(\mathrm{g} / \mathrm{cm}^{2}\right)\end{array}$ & $\begin{array}{c}\text { Standard } \\
\text { deviation }\end{array}$ & $\begin{array}{c}95 \% \text { conf. } \\
\text { interval }\end{array}$ & $\begin{array}{c}\text { Age } \\
\text { (years) }\end{array}$ & $\begin{array}{c}\text { Standard } \\
\text { deviation }\end{array}$ & $\begin{array}{c}95 \% \text { conf. } \\
\text { interval }\end{array}$ \\
\hline Female & 0.865 & 35.58 & 0.868 & 0.0201 & $\begin{array}{c}0.8653- \\
0.8709\end{array}$ & 34.71 & 1.479 & $\begin{array}{c}34.50- \\
34.92\end{array}$ \\
\hline Male & 0.949 & 38.72 & 0.951 & 0.0226 & $\begin{array}{c}0.9478- \\
0.9541\end{array}$ & 39.76 & 2.729 & $\begin{array}{c}39.38- \\
40.14\end{array}$ \\
\hline
\end{tabular}

Table 2. PBM and Age of occurrence for female and male lumbar spine

\begin{tabular}{|c|c|c|c|c|c|c|c|c|}
\hline \multirow{2}{*}{ Sex } & \multicolumn{2}{|c|}{ Original sample } & \multicolumn{6}{|c|}{ After bootstrapping } \\
\cline { 2 - 8 } & PBM $(\mathrm{g})$ & $\begin{array}{c}\text { Age } \\
\text { (years) }\end{array}$ & PBM (g) & $\begin{array}{c}\text { Standard } \\
\text { deviation }\end{array}$ & $\begin{array}{c}95 \% \text { conf. } \\
\text { interval }\end{array}$ & $\begin{array}{c}\text { Age } \\
\text { (years) }\end{array}$ & $\begin{array}{c}\text { Standard } \\
\text { deviation }\end{array}$ & $\begin{array}{c}95 \% \text { conf. } \\
\text { interval }\end{array}$ \\
\hline Female & 35.80 & 37.72 & 36.02 & 1.729 & $\begin{array}{c}35.77- \\
36.26\end{array}$ & 36.99 & 1.141 & $\begin{array}{c}36.83- \\
37.15\end{array}$ \\
\hline Male & 35.80 & 34.26 & 41.50 & 1.136 & $\begin{array}{c}41.35- \\
41.66\end{array}$ & 35.26 & 1.724 & $\begin{array}{c}35.02- \\
35.50\end{array}$ \\
\hline
\end{tabular}

Our results look different from the literature values [8]. Strictly speaking they are not comparable. If we look at the polynomial fittings carefully, we find that the peak values and the corresponding ages differ with the degree chosen. As the degree goes from 2 to 4, the ages shift toward the left and peak values tend to increase ( degree 1 does not give a maximum as it is a straight line). Most of the literature values are based on curve fitting by polynomials of degree 3 and 4, which are often very close and overlapping. Another very important point is that to calculate the peak value, a particular age group is selected, usually 20-29, which makes the age limited to twenties. Unless BMD or BMC values remain steady in this age group, the results are likely to be in error. Besides peak vaues have been obtained in the age group of thirties as well, especially for females [10-13]. By using bootstapping method we have created 100 samples from each data set and calculated the individual age at which the peak appears. That bootstrapping works well is proven by the fact that the results for original sample and the bootstrapped ones are quite close to one another.

From the graphs presented here it is evident through both experimental observation and statistical analysis that Loess is the best alternative for polynomial curve fitting. Bootstrapping is now an established method of resampling and is being widely used in different areas of research including environmental science where data collection may be difficult and expensive. The only precondition for the successful application of bootstrapping is that the original data sample must be reliable. Unfortunately we are not too happy with our data set as they were obtained from hospital sources, which included patients with and without bone weakness and some volunteers. We have not excluded any outliers for plotting curves.

The method proposed here seems to be logical but its robustness has to tested against reliable data sets of different countries.

\section{CONCLUSION}

Important as they are in predicting and diagnosing osteoporosis, the reference values for BMD should be consistent, reliable and uniform all throughout the world. In order to achieve that objective, the international experts on bone health should come to consensus on the following points:

1) Given that the pattern of variation of $\mathrm{BMD} / \mathrm{BMC}$ against Age is the same for all peoples, decision should made as to whether curve fitting should be done by polynomials of degree 3, 4 or by Loess method;

2) For calculating peak values, it has to be decided whether particular age groups should be chosen or individual values should be obtained on the basis of bootstap resampling;

3) Pressure should be brought to bear upon the manufacturers of different brand of instruments to make sure that all brands give the same value on measurement as is the case with other diagnostic and analytical equipments. 


\section{International Journal of Engineering Applied Sciences and Technology, 2019 \\ Vol. 4, Issue 7, ISSN No. 2455-2143, Pages 316-320 \\ Published Online November 2019 in IJEAST (http://www.ijeast.com)}

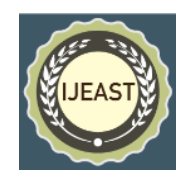

\section{ACKNOWLEDGMENT}

The author wishes to thank the chairman, Bangladesh Atomic Energy Commission, Dhaka for allowing us to use the facilities in the nuclear medicine centers at Cumilla and Rajshahi. Special thanks are due to the directors and their staff of those centers. We would also like to thank Dr. Atif $\mathrm{H}$. Rahman of Bangladesh University of Engineering and Technology for helping us with computation.

\section{REFERENCE}

[1] Carey J., and Delaney M. (2009). T-Scores and Z-Scores, in Clinical Reviews in Bone and Mineral Metabolism, (pp. 113-121).

[2] WHO Scientific Group on the Assessment of Osteoporosis at Primary Health Care Level (2004). www.who.int/chp/topics/osteoporosis.pdf

[3] Nguyen T., Maynard L., Towne B., et al. (2001). Sex differences in bone mass acquisition during growth: the Fels Longitudinal Study, in J Clin Densitom., (pp. 147157).

[4] Noon E., Singh S., Cuzick J., et al. (2010). Significant differences in UK and US female bone density reference ranges, in Osteoporos Int., ( pp. 1871-1880).

[5] Mikuls T., Saag K., Curtis J., et al. (2005). Prevalence of osteoporosis and osteopenia among African Americans with early rheumatoid arthritis: the impact of ethnicspecific normative data, in J Natl Med Assoc., (pp. 11551160).

[6] Hoiberg M., Nielsen T., Wraae K., et al. (2007). Population-based reference values for bone mineral density in young men, in Osteoporos Int., (pp.15071514).

[7] Ho-Pham L., Nguyen U., Pham H., et al. (2011). Reference Ranges for Bone Mineral Density and Prevalence of Osteoporosis in Vietnamese Men and Women, in BMC Musculoskeletal Disorders, (pp. 182).

[8] Banu D. A., (2015). Peak Bone Mineral Density Of Bangladeshi Men And Women, in IJSTR, (pp. 9-13).

[9] Deng H-W., Xu F-H., Davies K., et al. (2002). Differences in bone mineral density, bone mineral content, and bone areal size in fracturing and nonfracturing women, and their interrelationships at the spine and hip, in J Bone Miner Metab., (pp. 358-66).

[10] Tirtarahardja G., Setyohad B., Weynand L., et al. (2006). Bone Mineral Density Reference Values for Indonesian Men and Women, in ASBMR Lecture, American Society for Bone and Mineral Research Annual Meeting. 